FUELCELL2006-97225

\title{
THREE-DIMENSIONAL BASED MODEL OF A PLANAR SOFC FUELLED BY BIOMASS GAS
}

\author{
Stefano Cordiner \\ Massimo Feola \\ Vincenzo Mulone \\ Fabio Romanelli \\ University of Roma "Tor Vergata" \\ Department of Mechanical Engineering
}

\section{ABSTRACT}

Efficient and low polluting production of electricity and heat is an issue which cannot be postponed. Fuel cells, which convert the chemical energy stored in a fuel into electrical and thermal energy, are an efficient solution for such a problem. These devices rely on the combination of hydrogen and oxygen into water: oxygen is extracted from the air while hydrogen can be obtained from either fossil fuels or renewable sources.

The use of biomass as hydrogen source in connection with fuel cells is an argument of particular interest, since high temperature gasification processes are actually utilized. Solid Oxide Fuel Cells (SOFC), working at high temperatures, have become therefore an interesting candidate to realize the internal reforming of the feed gas from a gasifier. The reforming reaction occurs at the anode of the SOFC, upstream and separated from the fuel cell reaction. The section of the anode where reforming occurs is adjacent to the section where electrochemical reaction occurs. So, heat produced by the electrochemical reaction can be transferred internally with minimal losses.

Simulation models of the performance of SOFC stacks and biomass gasifiers are useful to visualize temperature, current and concentration distributions, which are difficult to measure by experimental techniques, allowing the definition of optimal choices in terms of geometries and operating conditions.

In this work, an analysis of a SOFC coupled with a biomass gasifier is performed. The objective of this study is the identification of the main effects of the operating conditions on the fuel cell performance in terms of efficiency, and the distribution of the main electro-thermalfluid-dynamics variables, namely current and temperature.

A gasifier model has been implemented to calculate the equilibrium compositions using the Gibbs free energy minimization method. The obtained results are directly used to estimate the inlet gas composition for the SOFC.
The SOFC has been modelled by a 3D approach (FLUENT), which solves the energy and mass transport and the internal reforming, coupled with a $0 \mathrm{D}$ electrolyte model which, starting from the local information in terms of gas composition, temperature and pressure, is able to predict the fuel cell performance in terms of electrical response and mass - energy fluxes.

The whole model has been applied to the analysis of an integrated SOFC-gasifier system to address a planar SOFC response by varying the gasifier operating conditions and the global system performance.

\section{NOMENCLATURE}

D Diffusion coefficient

E Cell operating voltage

$\mathrm{E}_{0} \quad$ Nernst voltage

F Faraday constant

G Gibbs free energy

$\mathrm{H}$ Enthalpy

$\mathrm{i}_{0, \mathrm{~A}} \quad$ Anode exchange current density

$\mathrm{i}_{0, \mathrm{C}} \quad$ Cathode exchange current density

j Current density

$\mathbf{j}_{\mathbf{i}} \quad \mathrm{i}$ - species mass flux

K Permeability tensor

$l_{\mathrm{e}} \quad$ Electrolyte thickness

$\mathrm{LHV}_{\mathrm{i}} \quad \mathrm{i}$ - fuel Low Heating Value

$\mathrm{m} \quad$ Amount of oxygen per mol of wood

$\dot{m} \quad$ Mass flow rate

M Molecular weight

MC Moisture content

n Normal versor

p Pressure 


$\begin{array}{ll}\mathrm{R} & \text { Gas constant } \\ \mathrm{R}_{\mathrm{e}} & \text { Electrolyte resistance } \\ \mathrm{S} & \text { Source term } \\ \mathrm{T} & \text { Temperature } \\ \mathbf{u} & \text { Velocity vector } \\ \mathrm{V} & \text { Voltage } \\ \mathrm{w} & \text { Amount of water per mol of wood } \\ \mathrm{X} & \text { Molar fraction } \\ \mathrm{Y} & \text { Mass fraction } \\ G r e e k & \text { Symbols } \\ \varepsilon & \text { Porosity } \\ \eta_{\mathrm{i}} & \text { Fuel cell losses } \\ \eta_{\mathrm{s} \text { sof }} & \text { SOFC efficiency } \\ \eta_{\mathrm{g}} & \text { Global efficiency } \\ \lambda & \text { Thermal Conductivity } \\ \mu & \text { Dynamic viscosity } \\ \mu_{\mathrm{f}} & \text { Fuel utilization } \\ v & \text { Kinematic viscosity } \\ \rho & \text { Density } \\ \sigma_{\mathrm{e}} & \text { Electrolyte conductivity } \\ \Phi & \text { Surface flux } \\ & \end{array}$

\section{Subscripts and superscripts}

i Species

\section{INTRODUCTION}

Fuel cells are currently considered an important answer to meet the future distributed electricity generation market needs. This is mainly due to their good characteristics in terms of efficiency and pollutant emissions.

Relevant progress has been made in the last decade to let the different fuel cells types enter the respective fields of application: automotive (Polymer Electrolyte Fuel Cells (PEFC), low temperature) and large scale stationary use (Molten Carbonate Fuel Cells (MCFC) and SOFC, high temperature). To this aim, many funded projects in Europe, USA and Japan have been carried out to assess the actual capabilities of such devices in terms of performance and reliability and follow the roadmap for a consistent cost reduction which is the absolute target to make them sustainable energy converters. Moreover, high temperature fuel cells, such as SOFC and MCFC, are especially attractive since, providing high temperature heat available at the exhaust, they can be efficiently used in cogeneration applications or for hybrid cycle purposes. It is also largely believed that combining traditional cycles with fuel cells could accelerate the market introduction of the latter.

Fuel flexibility constitutes a typical attractive characteristic of high temperature fuel cells [7]: these devices are in fact capable of operating with traditional light hydrocarbon fuels (e.g. methane) for their tolerance to carbon monoxide; internal reforming is also feasible and allows to design the system without any external fuel processor, although not for sulfur containing fuels.

In this context, SOFC fuel cells actually present remarkably attractive characteristics for their extremely high efficiency in converting chemical fuels directly into electrical power (over $40 \%$ [21]) and the high temperature exhaust heat which makes these devices ideal candidates to operate in combined cycles.

Moreover, the use of biomass to fuel SOFC could be an interesting and efficient solution: the integration of a downdraft gasifier with a SOFC has been proposed recently in $[11,16]$ : the hot exhaust gases coming from the gasifier are directly fed into the SOFC where the reforming and electrochemical reactions simultaneously occur. The SOFC exhaust gases are in turn provided to a combustor whose output is integrated with the gasifier: a simplified scheme of the cited system is provided in Figure 1.

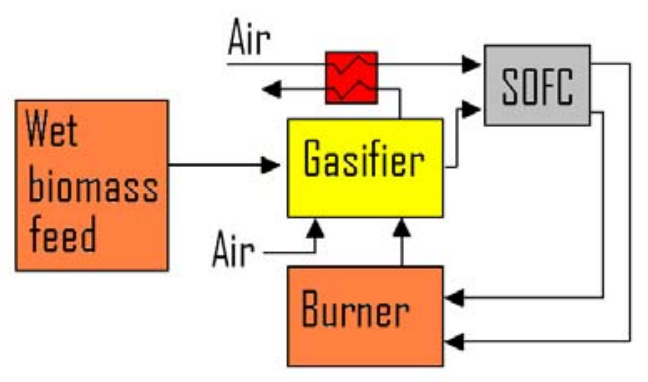

Fig.1. Simplified scheme of an integrated gasifierSOFC system

High temperature and water content operating conditions, typical of the integrated solutions, are needed to avoid any problems in terms of carbon deposition [20]; sulfur levels anyway, must be carefully controlled since the occurrence of even several ppm could cause the cell poisoning [14].

SOFC have been tested since 1930 as far as several configurations are concerned, the most widespread and tested being planar and tubular arrangements since 1960 [21]. However, a number of technological problems still need to be fixed for this kind of devices, basically related to the high operating temperature; a proper design of the cells configuration is in fact a challenging issue since materials need to be highly resistant but also to guarantee permeability to reactant-flow. Research and development are therefore required to characterize materials and their effect on the performance, and to address new and less expensive solutions.

To this aim, the availability of design tools able to correctly predict the temperature and fluid dynamic fields constitutes an effective way to understand the complex coupling among the different occurring phenomena and to test in a fast and cheap way a number of different cell and stack configurations to find the optimal solution in terms of performance/cost compromise. To completely exploit the full potential of simulation tools, 3D based models $[4,5,8,17$, $19,23]$ are the ideal candidates since they are able to predict 
the cell performance, the main fluid dynamic fields and current distribution whatever the geometry would be. 1D, simpler models have also been widely used and recently applied to the study of a downdraft gasifier-SOFC integrated system [10]. Although reliable in the performance prediction, these models lack for the needed degree of detail to constitute an effective design tool and provide the necessary information to perform, for example, a complete thermal stress analysis.

In this paper a simulation tool is proposed to predict the performance and the main electro-thermal-fluid dynamic fields of an integrated biomass fuelled gasifier-SOFC system. In the proposed approach the SOFC behaviour is predicted by means of a 3D model, while the gasifier is modelled by a OD equilibrium one, capable of providing the output starting from any biomass composition and water content. The model has been used to predict the whole system performance by varying gasifier operating conditions and address the main effects on the SOFC operation.

\section{MODELLING APPROACH}

The overall gasifier-SOFC model is constituted by two integrated modules, namely the $\mathrm{OD}$ gasifier equilibrium model and the 3D SOFC simulation model.

The OD gasifier model has been used to compute the inlet gas composition for the SOFC anode inlet; the SOFC module is instead constituted by a 3D submodel, taking into account the species and energy transport in the gas channels and in the porous electrodes, and an electrochemical submodel to solve the local charge/mass/energy problem in the electrolyte which provides the boundary conditions for the anode and cathode sides.

Finally, the SOFC output conditions are used to compute the potential integration heat and compare it to the guess initial value in a closed loop fashion.

The different modules and submodels present therefore rather different characteristics; details are provided below.

\section{2-1. 0D Gasifier Module}

The gasifier model is based on [24] The global gasification reaction can be written as it follows (eq. (1)) for a typical woody material whose composition can be retained as $\mathrm{CH}_{1.44} \mathrm{O}_{0.66}$ per carbon atom:

$$
\begin{aligned}
& \mathrm{CH}_{1.44} \mathrm{O}_{0.66}+w \mathrm{H}_{2} \mathrm{O}+\mathrm{mO}_{2}+3.76 m N_{2}= \\
& x_{1} \mathrm{H}_{2}+x_{2} \mathrm{CO}+x_{3} \mathrm{CO}_{2}+x_{4} \mathrm{H}_{2} \mathrm{O}+x_{5} \mathrm{CH}_{4}+3.76 m N_{2}
\end{aligned}
$$

where $\mathrm{w}$ represents the amount of water per mol of wood, $m$ the unknown amount of oxygen per mol of wood, $x_{i}$ the unknown molar fractions (per unit mole of carbon in the biomass fuel) of products. $\mathrm{w}$ is related to the Moisture Content (MC) by equation (2):

$$
w=\frac{24 M C}{18(1-M C)}
$$

In the model it is expected that residence time at the operating temperature is at least sufficient to le the pyrolisis products burn and achieve a gas-phase equilibrium; further relations need therefore to be introduced to find the six cited unknowns: the following reactions are then supposed to occur and to be at equilibrium, the equilibrium constants being $\mathrm{K}_{1}$ and $\mathrm{K}_{2}$ :

- $\mathrm{C}+2 \mathrm{H}_{2}=\mathrm{CH}_{4}$

- $\mathrm{CO}+\mathrm{H}_{2} \mathrm{O}=\mathrm{CO}_{2}+\mathrm{H}_{2}$

- $K_{1}=\frac{x_{5}}{x_{1}^{2}}$

- $K_{2}=\frac{x_{1} x_{3}}{x_{1}^{2}}$

Additional relations can be written in terms of elemental (eq. (7)-(9)) and energy balances (eq. (10)):

- $1=x_{2}+x_{3}+x_{5}$

- $2 w+1.44=2 x_{1}+2 x_{4}+4 x_{5}(8)$

- $\quad w+0.66+2 m=x_{2}+2 x_{3}+x_{4}$

- $d H_{\text {fwood }}+w d H_{H 2 O(l)}+d H_{i n t}=x_{1} d H_{H_{2}}+x_{2} d H_{C O}$

$+x_{3} d H_{C O 2}+x_{4} d H_{H 2 O(v a p)}+x_{5} d H_{C H 4}+3.76 m d H_{N 2}$

$\mathrm{dH}_{\mathrm{i}}$ being the sum of the heat of formation and enthalpy change for i-th species, $d H_{\text {int }}$ the integration heat flux. The equations can be re-arranged, and, by means of mathematical passages, the given set can be reduced to a 3 equation one (one linear and two non-linear) which have been solved by means of the Newton-Raphson method; operating temperature, MC percentage, integration heat flux $\mathrm{dH}_{\text {int }}$ and the specific heats of all the examined species represent the input parameters for the model.

\section{2-2. $\quad$ SOFC Module}

The SOFC module has been used to predict the behavior of the smallest repeated geometrical element (unit cell), so realizing the unit cell approach. By the use of this approach, mass and energy balances can be solved for a single cell and extended to the entire stack having assumed all the cells behaving in the same way. The SOFC module is composed by the 3D and electrochemical submodules. The overall module is based on the following main hypothesis:

- Planar co-flow configuration;

- Laminar flow;

- Steady state;

- Isotropic porous media;

- Infinite electrodes conductivity;

- Adiabatic channel

- $\quad$ No radiative heat exchange.

3D approach, although computationally demanding, allows to obtain accurate information on the distribution of the main thermal-fluid-dynamic variables, and therefore the unique candidate design tool based on modelling.

Details of the SOFC submodels are provided in the following sections.

\section{2-2-1. 3D fluid dynamic submodel}

The 3D fluid dynamic submodel is based on the implementation of mass, momentum and energy equations written for mixtures of seven $\left(\mathrm{N}_{\mathrm{g}}\right)$ gaseous species $\left(\mathrm{H}_{2}, \mathrm{O}_{2}\right.$, 
$\mathrm{H}_{2} \mathrm{O}, \mathrm{CH}_{4}, \mathrm{CO}, \mathrm{CO}_{2}, \mathrm{~N}_{2}$ ). This submodel is used to represent the flow into the fuel and oxidant channels and porous electrodes. The whole equation set assumes the following form:

- Mass:

o $\quad \nabla \cdot \rho \mathbf{u}=0$

- $\quad$ i-th species $\left(\mathrm{i}=1, \mathrm{~N}_{\mathrm{g}}\right)$ :

o $\nabla \cdot \rho Y_{i} \mathbf{u}-\nabla \cdot\left(\rho D_{i} \nabla Y_{i}\right)=S_{i}$

where $\mathrm{Y}_{\mathrm{i}}$ represents the examined species mass fraction, $D_{i}$ its diffusion coefficient and $S_{i}$ its source term, which depends on the occurring chemical mechanism.

Within the proposed fluid-dynamic submodel, the internal reforming chemical process has been modelled by the introduction of the homogeneous phase methane reforming reaction (13) and the Water-Gas Shift (WGS) one (14) [18]:

- $\mathrm{CH}_{4}+\mathrm{H}_{2} \mathrm{O} \rightarrow 3 \mathrm{H}_{2}+\mathrm{CO}$

- $\mathrm{CO}+\mathrm{H}_{2} \mathrm{O} \leftrightarrow \mathrm{H}_{2}+\mathrm{CO}_{2}$

Reaction (13) has been modelled by a kinetic approach whose parameter set refers to [2], while (14) is considered to be always at equilibrium [10].

- Momentum:

o $\quad \nabla \cdot(\rho \mathbf{u u}-\mu \nabla \mathbf{u})=-\nabla\left(p+\frac{2}{3} \mu \nabla \cdot \mathbf{u}\right)-\frac{\mu}{K}(\varepsilon \mathbf{u})$

$\mathrm{K}$ being the permeability tensor, which allows to take into account the electrodes porosity.

- Enthalpy:

o $\quad \nabla \cdot(\rho \mathbf{u} h-\lambda \nabla T)=S_{h}$

$\lambda$ represents the local thermal conductivity: it generally depends on composition and gas pure species thermal conductivities, which are defined by means of the ideal gas kinetic theory. In the electrodes, $\lambda$ expression takes into proper account the solid thermal conductivity $\left(\lambda_{\mathrm{s}}=2.25\right.$ $\mathrm{W} / \mathrm{mK}$ [23]) using an average gas-solid mass-weighted value by means of electrode porosity $\varepsilon$.

$\mathrm{S}_{\mathrm{h}}$ represents the energy source term which is related to the species change by $S_{h}=\sum_{i}^{N g} h_{i} S_{i}$, since $h_{i}$ takes into account both sensible and formation contributions.

\section{2-2-2. Electrochemical submodel}

The 3D equations for the species and energy transport (eq. (12) and (16)), need a dedicated model to properly take into account the mass/energy/current problem across the electrolyte. To this aim, the previously reported equation set has been coupled to a $1 \mathrm{D}$ electrochemical model $[1,6,8,10,15,21,22]$.
The electrochemical submodule main modelling arguments are based on the representation of the electrochemical reaction (17) which basically governs the cathode and anode mass fluxes (and the related charge motion).

$$
\text { o } \mathrm{H}_{2}+\frac{1}{2} \mathrm{O}_{2} \rightarrow \mathrm{H}_{2} \mathrm{O}
$$

Ideally, the occurrence of reaction (17) gives a Nernst cell voltage $\left(E_{0}\right)$ which is a function of temperature and composition:

$$
0 \quad E_{0}=\frac{\Delta G(T)}{2 F}+\frac{R \cdot T}{2 F} \cdot \ln \left[\frac{\left(p_{\mathrm{H} 2} / p_{0}\right) \cdot\left(p_{\mathrm{O} 2} / p_{0}\right)^{\frac{1}{2}}}{\left(p_{\mathrm{H} 2 \mathrm{O}} / p_{0}\right)}\right]
$$

$\Delta \mathrm{G}(\mathrm{T})$ at a given temperature is provided by an interpolation of tabular values.

As a matter of fact, the actual cell voltage E differs from the Nernst one for the activation $\left(\eta_{\text {act }}\right)$ and ohmic losses $\left(\eta_{\text {ohm }}\right)$ :

$$
\text { ○ } E=E_{0}-\eta_{a c t}-\eta_{\text {ohm }}
$$

Activation and ohmic losses express the occurrence of irreversible phenomena respectively due to the slowness of reactions taking place on the electrodes, and the resistance to the ion flow through the electrolyte.

Activation losses at the anode and cathode ( $\eta_{\text {act, } A}$ and $\eta_{\text {act,C }}$ respectively) are modelled by a Butler-Volmer approach:

$$
\begin{array}{ll}
0 & \eta_{a c t, A}=\frac{2 R T}{F} \sinh ^{-1}\left(\frac{j}{2 i_{0 A}}\right) \\
0 & \eta_{a c t, C}=\frac{2 R T}{F} \sinh ^{-1}\left(\frac{j}{2 i_{0 C}}\right)
\end{array}
$$

where $\mathrm{j}$ represents the actual current density and $\mathrm{i}_{0, \mathrm{C}}$ and $\mathrm{i}_{0, \mathrm{~A}}$ are provided by the following [10]:

$$
\begin{aligned}
0 & i_{0, A}=5.5 \times 10^{4}\left(\frac{p_{\mathrm{H}_{2}}}{p_{0}}\right)\left(\frac{p_{\mathrm{H}_{2} \mathrm{O}}}{p_{0}}\right) \exp \left(-\frac{100 \times 10^{3}}{R T}\right)(22) \\
0 & i_{0, C}=7.0 \times 10^{4}\left(\frac{p_{\mathrm{O}_{2}}}{p_{0}}\right)^{0.25} \exp \left(-\frac{120 \times 10^{3}}{R T}\right)
\end{aligned}
$$

Ohmic losses are computed by:

$$
\text { o } \quad \eta_{\text {ohm }}=R_{e} \cdot j
$$

where the electrolyte resistance $R_{e}$ is obtained as

$$
\text { o } \quad R_{e}=\frac{l_{e}}{\sigma_{e}},\left[\Omega \cdot \mathrm{cm}^{2}\right]
$$

$l_{e}$ and $\sigma_{e}$ being the electrolyte thickness and conductivity; the latter can be expressed as:

$$
\text { o } \quad \sigma_{e}=\beta_{1} \cdot \exp \left(\frac{-\beta_{2}}{T}\right),\left[\frac{1}{\Omega \cdot c m}\right]
$$

The electrochemical submodule, therefore, starting from an explicitly provided actual cell voltage $\mathrm{E}$, is able to compute the local current density and the related mass and energy fluxes at the boundary between the electrodes and the electrolyte:

- Cathode side: 


$$
\begin{array}{ll}
0 & \mathbf{j}_{O_{2}}=-\frac{\mathbf{j}}{4 F} \cdot M_{O_{2}} \\
0 & \boldsymbol{\Phi}_{\text {mass_c }}=\mathbf{j}_{\mathbf{O}_{2}} \quad(28) \\
0 & \boldsymbol{\Phi}_{\text {energy_c }}=(1.25-E) \mathbf{j}
\end{array}
$$

In equation (29) 1.25 represents $(-\Delta \mathrm{H} / 2 \mathrm{~F})$ of hydrogen reaction (17) which can be retained almost constant by varying temperature [13].

- Anode side:

$$
\begin{array}{ll}
\mathrm{o} & \mathbf{j}_{\mathrm{H}_{2}}=-\frac{\mathbf{j}}{2 F} \cdot M_{\mathrm{H}_{2}} \\
\mathrm{o} & \mathbf{j}_{\mathrm{H}_{2} \mathrm{O}}=\frac{\mathbf{j}}{2 F} \cdot M_{\mathrm{H}_{2} \mathrm{O}} \\
\mathrm{o} & \boldsymbol{\Phi}_{\text {mass_a }}=-\boldsymbol{\Phi}_{\text {mass_c }}
\end{array}
$$

\section{2-3. 3D Fluid Dynamic Submodel Boundary \\ Conditions}

The 3D equation set boundary conditions are provided as described below:

- Mass:

o Inlet: the mass flow rate are directly imposed on the anode and cathode inlet sections based on the local density value computed by the gas law;

o Electrode/electrolyte interface: the cathode and anode mass exchange, computed by the electrochemical module, is provided by means of $\boldsymbol{\Phi}_{\text {mass_a }}$ and $\boldsymbol{\Phi}_{\text {mass_c }}$ previously described in equations (28) and (32).

$$
\text { o Wall: } \boldsymbol{\Phi}_{\text {mass }}=0 \text {. }
$$

- Gaseous species:

o Inlet: concentrations $\left(Y_{i}\right)$ are imposed homogeneously on the inlet section;

o Electrode/electrolyte interface: the gaseous species mass fluxes $\mathbf{j}_{\mathbf{i}}$ (equations (27), (30), (31)) are directly provided;

o Wall: $\mathbf{j}_{\mathbf{i}}=0$;

o Outlet: $\frac{\partial Y_{i}}{\partial n}=0$.

- Momentum:

o Inlet: $|\mathbf{u}|=u_{0}$ constant on the inlet section;

o Electrode/electrolyte interface and wall: $\mathbf{u}_{\text {wall }}=0$ which can be directly implemented since the flow regime is laminar within the gas channels and diffusion layers;

o Outlet: atmospheric pressure is imposed homogeneously on the outlet section.

- Enthalpy:

o Inlet: $\mathrm{T}=\mathrm{T}_{0}$ constant on the inlet section $\left(\mathrm{T}_{0}\right.$ referred as inlet temperature);

o Electrode/electrolyte interface: heat released by the occurrence of the electrochemical reaction (17) is provided at the gas catalyst/diffusion layers interface imposing the related energy flux described in equation (29);

o Wall: $\boldsymbol{\Phi}_{\text {energy }}=0$;
o Outlet: $\frac{\partial h}{\partial n}=0$.

\section{2-4. Computational Tools}

The modules described in the previous sections, depending on the specific characteristics, have been implemented into different computational environments.

The OD gasifier problem has been solved by an implementation of Newton-Raphson algorithm into a FORTRAN subroutine.

The 3D fluid dynamics submodel equations have been discretized and solved by the finite volume approach by means of the commercial Finite Volume CFD code FLUENT 6.2 [9], which allows to easily manage the fluid dynamic equations for ideal gas mixtures and the related thermodynamic and transport properties as functions of composition and temperature.

The electrochemical submodel has been built as a FLUENT native User Defined Function (UDF).

The whole framework is managed by a main program, whose flow diagram is reported in Figure 2.

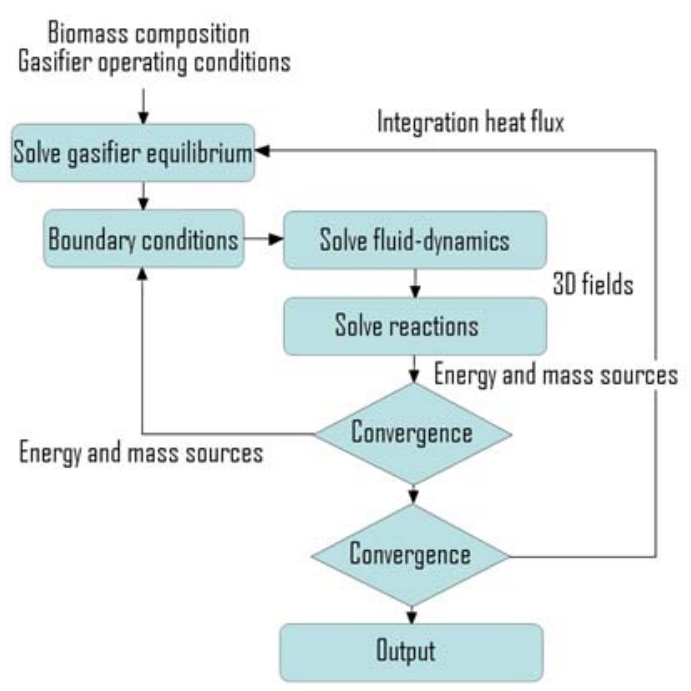

Fig. 2. Whole numerical model flow diagram

\section{MODEL SETUP}

The gasifier and SOFC electrochemical modules have been separately set up: the gasifier has been validated against experimental results available in literature, while the constant set of the electrochemical module has been chosen to characterize the SOFC module polarization characteristic curve as a typical planar YSZ cell. Further details are provided below. 


\section{3-1. Gasifier Model Validation}

The gasifier model has been applied as a stand-alone numerical code to predict the output of a woody material fed and adiabatic gasifier $\left(\mathrm{dH}_{\mathrm{int}}=0\right)$.

The MC effect on the outlet gasifier composition is reported in Figure 3 where the dry basis molar fractions of the species are plotted against the MC.

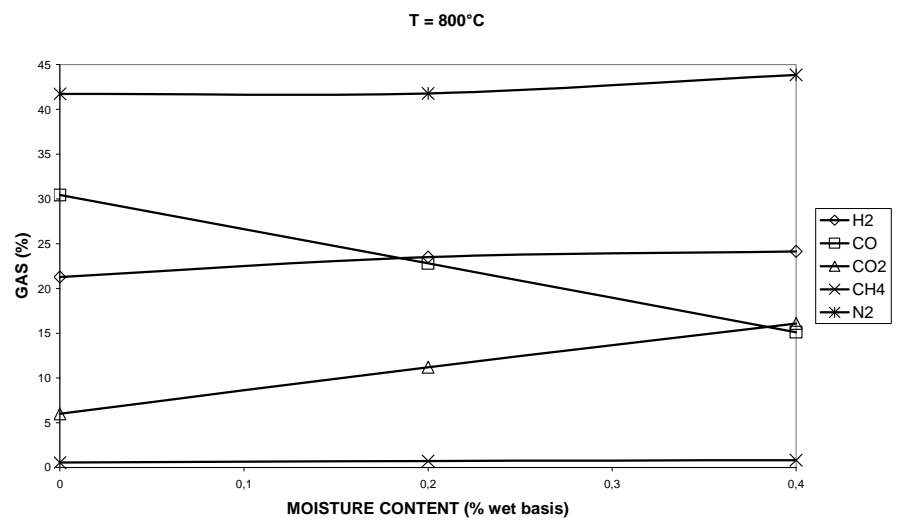

Fig. 3. MC effect on outlet gasifier composition at $800^{\circ} \mathrm{C}$

It can be affirmed that:

- $\mathrm{CH}_{4}$ fraction has a low value (1\% about) and an almost constant trend;

- $\quad$ Produced $\mathrm{H}_{2}$ and $\mathrm{CO}_{2}$ increase with $\mathrm{MC}$, as expected;

- $\quad \mathrm{CO}$ diminishes with MC, as expected by the increase of $\mathrm{CO}_{2}$.

The numerical output values have been compared to experimental data referring to [3]. Results related to $800^{\circ} \mathrm{C}$ and 20\% MC operating conditions are reported in Table 1 in terms of molar compositions. It can be generally said that:

- the predicted $\mathrm{H}_{2}$ fraction is consistently overestimated with regard to the experimental one;

- $\quad$ the CO is slightly underestimated.

$\mathrm{CO}$ and $\mathrm{H}_{2}$ molar composition determine the output gas calorific value, since methane composition is negligible; the contemporary occurrence of overestimation and underestimation of $\mathrm{H}_{2}$ and $\mathrm{CO}$ gives a light beneficial effect on the calorific value prediction.

\begin{tabular}{|c|c|c|}
\hline & Present work Num. & [3] Exp. \\
\hline $\mathbf{H}_{\mathbf{2}}$ & 23.51 & 15.23 \\
\hline $\mathbf{C O}$ & 22.78 & 23.04 \\
\hline $\mathbf{C H}_{\mathbf{4}}$ & 0.72 & 1.58 \\
\hline $\mathbf{C O}_{\mathbf{2}}$ & 11.19 & 16.42 \\
\hline $\mathbf{N}_{\mathbf{2}}$ & 41.78 & 42.31 \\
\hline
\end{tabular}

Tab. 1. Experimental-Numerical comparison for $800^{\circ} \mathrm{C}$ and $20 \%$ MC gasifier operating conditions

The predicted calorific values are also reported in Table 2: a $8.7 \%$ error corresponds to Table 1 compositions, while an increase or decrease of operating temperature respectively gives better and worse results than $800^{\circ} \mathrm{C}$.

\begin{tabular}{|l|l|l|l|}
\hline & $\begin{array}{l}\text { Calorific value } \\
{\left[\mathbf{M J} / \mathbf{m}^{3}\right] \text { Pr. }} \\
\text { Work, Num. }\end{array}$ & $\begin{array}{l}\text { Calorific value } \\
{\left[\mathbf{M J} / \mathbf{m}^{3}\right][\mathbf{3}]} \\
\text { Exp. }\end{array}$ & $\begin{array}{l}\text { Error } \\
{[\%]}\end{array}$ \\
\hline $750^{\circ} \mathrm{C}$ & 5.5 & 4.9 & 10.7 \\
\hline $800^{\circ} \mathrm{C}$ & 5.3 & 4.8 & 8.7 \\
\hline $900^{\circ} \mathrm{C}$ & 4.9 & 4.6 & 6.1 \\
\hline
\end{tabular}

Tab. 2. Experimental-Numerical comparison for $20 \%$ MC gasifier operating conditions

The use of $0 \mathrm{D}$ equilibrium approach has been therefore retained suitable to represent the gasifier operation at high temperature as far as the calorific value prediction is concerned.

\section{3-2. SOFC Electrochemical Submodule Setup}

The electrochemical submodule has been set-up and validated with regard to literature available similar models [1, $6,8,10,15,21,22]$.

The main parameters characterizing the YSZ electrolyte within the examined module are reported in Table 3 , and assume fairly assessed values.

\begin{tabular}{|l|l|l|}
\hline & Value & Units \\
\hline$\beta_{\mathbf{1}}$ & 334 & {$[1 /(\Omega \mathrm{cm})]$} \\
\hline $\boldsymbol{\beta}_{\mathbf{2}}$ & 10300 & {$[\mathrm{~K}]$} \\
\hline Electrolyte thickness $\left(\mathbf{l}_{\mathbf{e}}\right)$ & 40 & $\mu \mathrm{m}$ \\
\hline
\end{tabular}

Tab. 3. Electrochemical model parameters

The stand-alone electrochemical submodule output are finally plotted in Figure 4 where the current-voltage characteristics are reported for different typical operating temperatures.

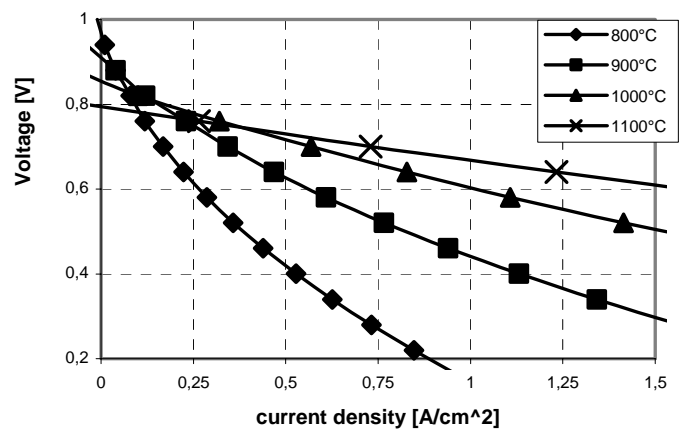

Fig. 4. Polarization curves of an anode supported SOFC with fixed temperatures and gas fractions.

The plotted polarization curves clearly do not take into account the concentration losses which are directly computed by the 3D fluid dynamic sub-module by a modification of the local Nernst voltage value.

\section{ANALYSIS OF RESULTS}

The overall model has been applied to the analysis of a SOFC-gasifier integrated system (Figure 1) fed by woody material biomass $\mathrm{CH}_{1.44} \mathrm{O}_{0.66}$. The model flow- 
diagram refers to Figure 2, $\mathrm{dH}_{\text {int }}$ being the integration heat flux. $\mathrm{dH}_{\text {int }}$ is defined as the heat provided by the SOFC anode off-gas combustion.

The heat recovery from anode off-gas allows the gasifier to operate with high MC and almost without air. The examined operating conditions therefore, named $\mathrm{A}$ and $\mathrm{B}$ respectively, refer to $30 \%$ and $40 \% \mathrm{MC}$ and $900{ }^{\circ} \mathrm{C}$.

An anode supported planar SOFC arrangement has been considered in a co-flow configuration, whose transversal section dimensions are reported in Figure 5. A sketch of the 3D computational domain (discretized into about 100000 cells) is given in Figure 6, and the main operating and geometrical conditions are provided in Tables 4 and 5.

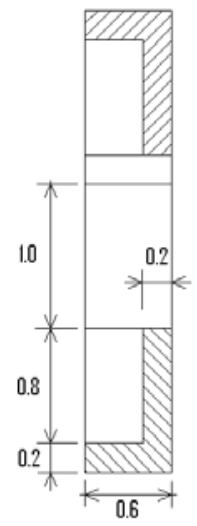

Fig. 5. SOFC transversal section dimensions

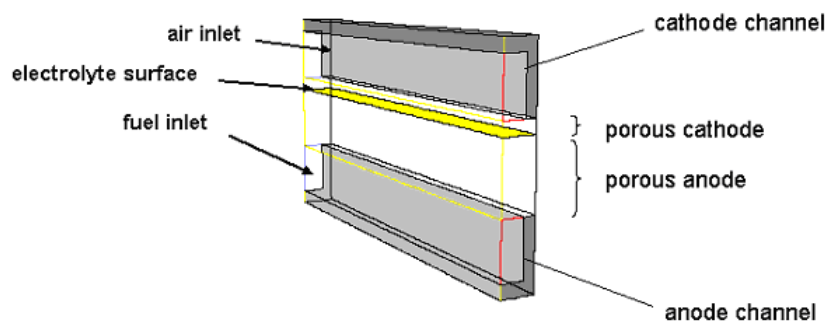

Fig. 6. Schematic of an anode supported SOFC

\begin{tabular}{|l|l|l|}
\hline & Value & Units \\
\hline Cell length & 71 & $\mathrm{~mm}$ \\
\hline Gas channel height & 0.8 & $\mathrm{~mm}$ \\
\hline Gas channel width & 0.8 & $\mathrm{~mm}$ \\
\hline Rib & 0.4 & $\mathrm{~mm}$ \\
\hline Anode electrode thickness & 1 & $\mathrm{~mm}$ \\
\hline Cathode electrode thickness & 0.2 & $\mathrm{~mm}$ \\
\hline Electrode porosity & 0.4 & \\
\hline
\end{tabular}

Tab. 4. SOFC geometrical characteristics

\begin{tabular}{|l|l|l|}
\hline & Value & Units \\
\hline $\begin{array}{l}\text { Anode and Cathode inlet } \\
\text { pressure }\end{array}$ & 1 & atm \\
\hline $\begin{array}{l}\text { Anode and Cathode inlet } \\
\text { temperature }\end{array}$ & 1173 & $\mathrm{~K}$ \\
\hline Cell voltage & 0.65 & $\mathrm{~V}$ \\
\hline Cathode/Anode mass flow ratio & 15 & - \\
\hline
\end{tabular}

Tab. 5. SOFC operating conditions

The $0.65 \mathrm{~V}$ operating condition has been selected as representative of an average load condition.

The SOFC case A and B inlet gas compositions (computed by the gasifier module), given in Table 6, differ mainly in the $\mathrm{H}_{2} / \mathrm{CO}$ ratio as a logical consequence of the different Moisture Content; it is worth noting that the availability of integration heat for the gasifier allows to operate with high MC and to obtain gas practically without $\mathrm{CH}_{4}$ and $\mathrm{N}_{2}$.

\begin{tabular}{|l|l|l|}
\hline & Case A & Case B \\
\hline $\mathrm{MC}$ & 0.3 & 0.4 \\
\hline $\mathrm{H}_{\mathbf{2}}$ (mol dry basis) & 0.54 & 0.56 \\
\hline $\mathrm{CO}$ (mol dry basis) & 0.44 & 0.39 \\
\hline $\mathrm{CO}_{2}$ (mol dry basis) & 0.02 & 0.06 \\
\hline $\mathrm{CH}_{4}$ (mol dry basis) & 0 & 0 \\
\hline $\mathbf{N}_{\mathbf{2}}$ (mol dry basis) & 0 & 0 \\
\hline $\mathrm{H}_{2}$ /CO molar ratio & 1.23 & 1.44 \\
\hline
\end{tabular}

Tab. 6. SOFC inlet gas composition

As far as the SOFC is concerned, the main performance indicators rely on fuel utilization $\mu_{\mathrm{f}}$ and efficiency $\eta_{\text {sofc }}$ whose definitions are (31) and (32):

$$
\mu_{f}=\frac{\sum_{i}\left(\dot{m}_{i}^{\text {in }}-\dot{m}_{i}^{\text {out }}\right)}{\sum_{i} \dot{m}_{i}^{\text {in }}}
$$

where $\dot{m}_{i}$ terms represent the i-th fuel component $\left(\mathrm{CO}\right.$ or $\left.\mathrm{H}_{2}\right)$ mass flow rates .

$$
\eta_{\text {SOFC }}=\frac{P_{e l}}{\sum_{i} \dot{m}_{i}^{\text {in }} L H V_{i}}
$$

$\mathrm{P}_{\mathrm{el}}$ being the output electrical power and $\mathrm{LHV}_{\mathrm{i}}$ the ith fuel component Low Heating Value (Table 7).

The SOFC performance indicators are summarized in Table 8.

\begin{tabular}{|l|l|l|}
\hline & Value & Units \\
\hline $\mathbf{C O}$ & 10106 & $\mathrm{~kJ} / \mathrm{kg}$ \\
\hline $\mathbf{H}_{\mathbf{2}}$ & 120910 & $\mathrm{~kJ} / \mathrm{kg}$ \\
\hline $\mathbf{C H}_{\mathbf{4}}$ & 50144 & $\mathrm{~kJ} / \mathrm{kg}$ \\
\hline $\begin{array}{l}\text { Biomass (Wood) } \\
\mathbf{C H}_{\mathbf{1 . 4 4}} \mathbf{O}_{\mathbf{0 . 6 6}}\end{array}$ & 15940 & $\mathrm{~kJ} / \mathrm{kg}$ \\
\hline
\end{tabular}

Tab. 7. Fuels Low Heating Values 


\begin{tabular}{|l|l|l|}
\hline & Case A & Case B \\
\hline Mean current density [A/cm $\left.{ }^{2}\right]$ & 0.3 & 0.28 \\
\hline$\mu_{\mathrm{f}}[\%]$ & 61 & 57 \\
\hline$\eta_{\text {SOFC }}[\%]$ & 31.2 & 34.3 \\
\hline
\end{tabular}

Tab. 8. SOFC performance indicators

Case A and B fuel utilizations deviate from ideal values to satisfy the gasifier balance. It is evident, therefore, that the pure SOFC efficiency $\eta_{\mathrm{SOFC}}$ is not allowed to obtain itself an optimum value. It is also worth noting that the SOFC performance increases with MC, whereas a higher efficiency is promoted by a more favorable $\mathrm{H}_{2} / \mathrm{CO}$ inlet molar ratio.

From a global point of view, however, the system overall performance must be examined to have the actual evaluation of efficiency. So, the global efficiency $\eta_{\mathrm{g}}$ must be introduced as follows:

$$
\eta_{g}=\frac{P_{e l}}{\sum_{i} \dot{m}_{\text {biomass }}^{\text {in }} L H V_{\text {biomass }}}
$$

where the output power is compared to the gasifier input thermal power.

The system efficiency increases with respect to the $\eta_{\text {SOFC }}$ since the exploitation of the gasifier integration heat has, obviously, a positive effect letting the whole system obtaining pretty high absolute performance (Table 9).

\begin{tabular}{|l|l|l|}
\hline & Case A & Case B \\
\hline$\eta_{\mathrm{g}}[\%]$ & 42.2 & 45.8 \\
\hline
\end{tabular}

Tab. 9. System performance indicators

The use of 3D computational fluid dynamics allows, furthermore, to obtain a description of what actually occurs within the gas channels, electrodes and electrolyte: the model therefore effectively acts as a valid substitute of not easily realizable experimental techniques. Current density on the electrolyte is highlighted in Figure 7 (top view): the current first increases and then diminishes along the channel; this behavior is due to the opposite effects of reduction of $\mathrm{H}_{2}$ concentration (Figure 8, side view) and increase of temperature (Figure 9, side view) which respectively promotes and inhibits the local current; temperature, in turn, depends on the electrochemical reactions heat release, displayed in Figure 10 (top view).

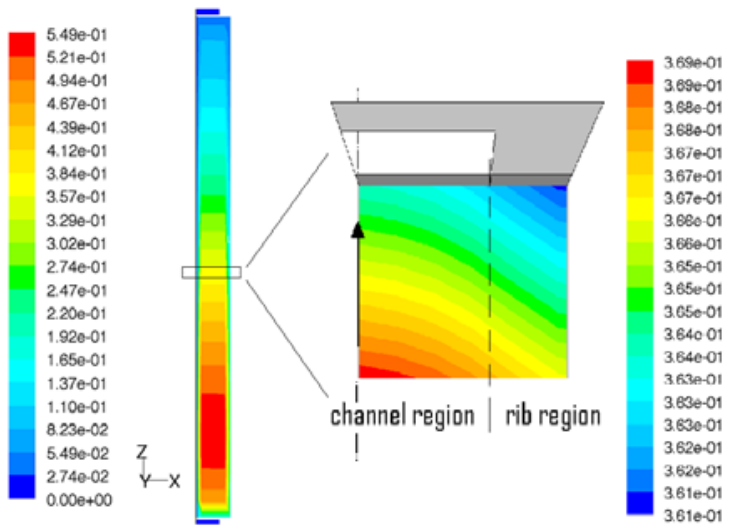

Fig. 7. Current $\left[\mathrm{A} / \mathrm{cm}^{2}\right]$ distribution and detail on the electrolyte (case $A$, inlet on the bottom)

The effect of rib presence on $\mathrm{H}_{2}$ concentration field is highlighted in the detail of Figure 8 with regard to a transversal section. It is worth noting that an $\mathrm{x}$-direction net diffusion flux occurs to serve the rib-corresponding electrode region. Simultaneously, a varying y-direction diffusion flux towards the electrolyte gives a non-uniform current distribution, highlighted in Figure 7, whose profile depends on geometrical and material characteristics.

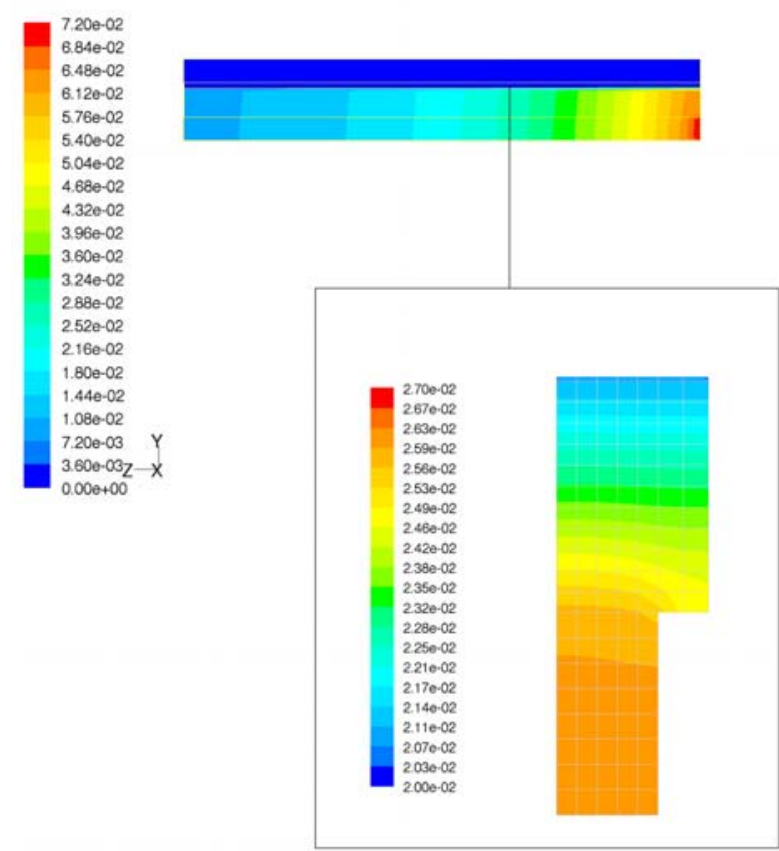

Fig. 8. $\mathrm{H}_{2}$ distribution and detail on a transversal section (case $A$, inlet on the right)

The electrodes influence is recognizable in the temperature distribution by the occurrence of vertical sloping iso-lines, due to the extremely low velocities in those porous regions. The model, then, would constitute an effective base to evaluate the local thermal-stress which constitute at present time the main technological aspect to improve for SOFC development.
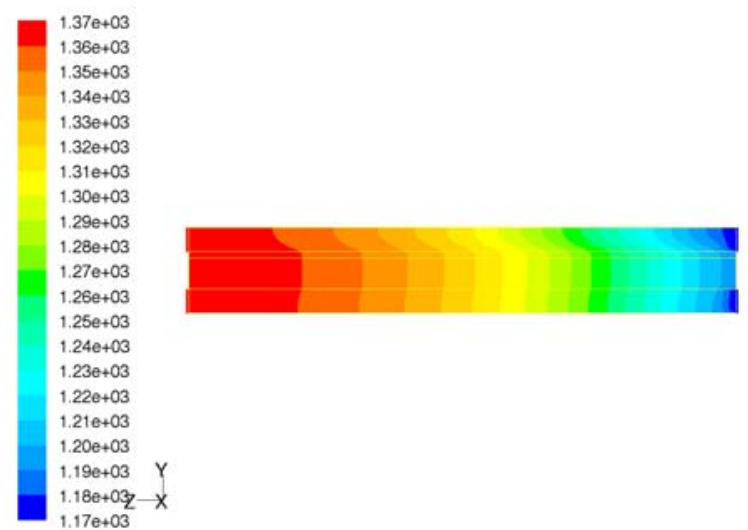

Fig. 9. Temperature distribution $[\mathrm{K}]$ (case $A$, inlet on the right) 
Water gas shift reaction, occurring in the channels, is responsible for the conversion of $\mathrm{CO}$ and $\mathrm{H}_{2} \mathrm{O}$ into $\mathrm{H}_{2}$ and $\mathrm{CO}_{2}$. The electrochemical release of $\mathrm{H}_{2} \mathrm{O}$ along the channel (Figure 11, side view) shifts the equilibrium giving an increase in $\mathrm{H}_{2}$ and $\mathrm{CO}_{2}$ (Figure 12) and the possibility of exploiting $\mathrm{CO}$ whose diminishing profile is also evident (Figure 13).
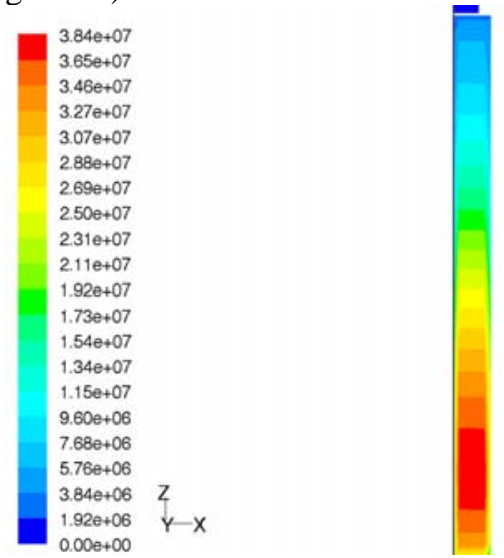

Fig. 10. Electrochemical heat release distribution $\left[\mathrm{W} / \mathrm{m}^{3}\right]$ (case $\mathrm{A}$, inlet on the bottom)

$$
\begin{aligned}
& 3.11 \mathrm{e}-01 \\
& 2.96 \mathrm{e}-01 \\
& 2.80 \mathrm{e}-01 \\
& 2.84 \mathrm{e}-01 \\
& 2.49 \mathrm{e}-01 \\
& 2.33 \mathrm{e}-01 \\
& 2.18 \mathrm{e}-01 \\
& 2.02 \mathrm{e}-01 \\
& 1.87 \mathrm{e}-01 \\
& 1.71 \mathrm{e}-01 \\
& 1.56 \mathrm{e}-01 \\
& 1.40 \mathrm{e}-01 \\
& 1.24 \mathrm{e}-01 \\
& 1.09 \mathrm{e}-01 \\
& 9.33 \mathrm{e}-02 \\
& 7.78 \mathrm{e}-02 \\
& 6.22 \mathrm{e}-02 \\
& 4.67 \mathrm{e}-02 \\
& 3.11 \mathrm{e}-02 \quad \mathrm{Y} \\
& 1.56 \mathrm{e}-02 \mathrm{Z}-\mathrm{X} \\
& 0.00 \mathrm{e}+00
\end{aligned}
$$

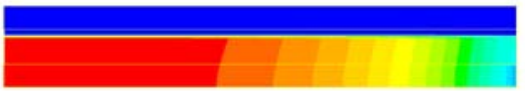

Fig. 11. $\mathrm{H}_{2} \mathrm{O}$ distribution (case $\mathrm{A}$, inlet on the right)

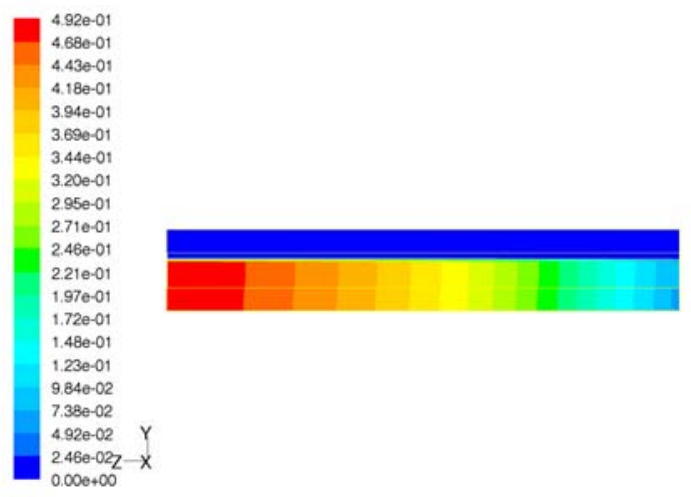

Fig. 12. $\mathrm{CO}_{2}$ distribution (case $\mathrm{A}$, inlet on the right)

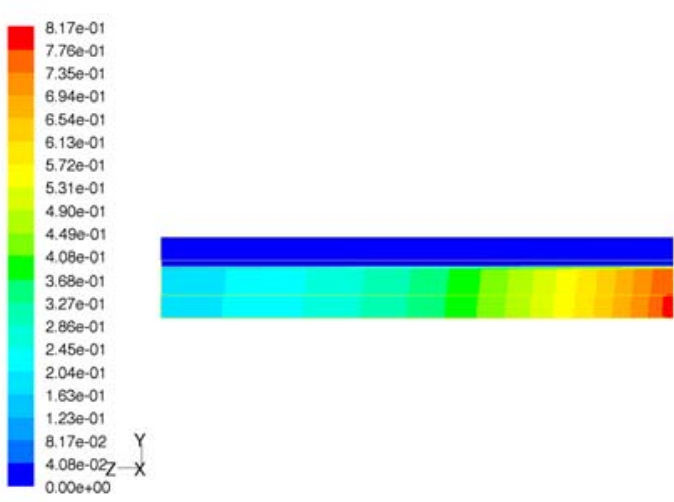

Fig. 13. CO distribution (case $A$, inlet on the right)

On the cathode side, the oxygen depletion can be highlighted (Figure 14): the high Anode/Cathode mass flow ratio clearly gives a high concentration on the outlet, as well as more sloping iso-lines.

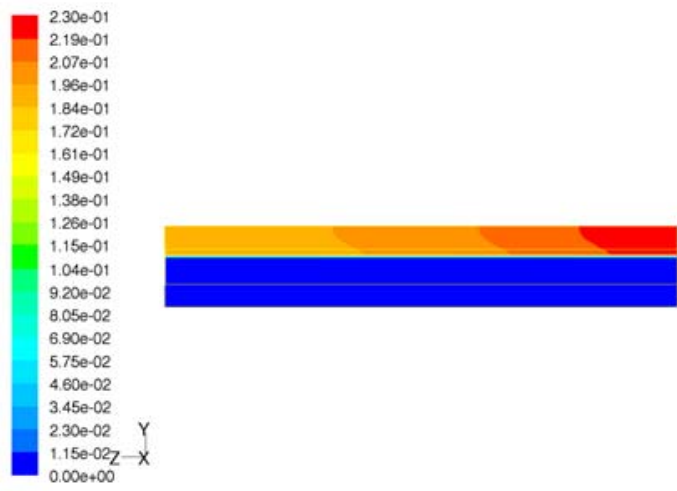

Fig. 14. $\mathrm{O}_{2}$ distribution (case $\mathrm{A}$, inlet on the right)

The obtainment of both quantitative information and the accurate description of all the thermal-fluid-dynamics fields, and especially of temperature, within the cell, highlights the potential of the proposed numerical model which could easily constitute the key element of a comprehensive Computer Aided Engineering (CAE) tool for integrated SOFC systems design and operation prediction. The further great advantage of the proposed approach consists of the possibility of an immediate application to any SOFC geometry and fluid-dynamic arrangement with no major complications.

\section{CONCLUSIONS}

A numerical model has been proposed to evaluate the performance of an integrated biomass-gasifier-SOFC system under different operating conditions.

The model is constituted by several modules, namely a $0 \mathrm{D}$ gasifier one and a 3D model based SOFC one; each module is characterized by different accuracy and complexity depending on the degree of detail required by the specific phenomena occurring and the typical length scales of variation of the analyzed variables.

Once setup, the whole model has been applied to the analysis of a system fed by an integrated gasifier operating at $900^{\circ} \mathrm{C}$ and different water content conditions. The main results indicate that: 
- In spite of the integration, the SOFC is allowed to operate at fairly high fuel utilizations, giving therefore already stand-alone acceptable performance in terms of efficiency;

- The SOFC efficiency increases with the Moisture Content of the fed biomass since a mixture with a more favorable $\mathrm{H}_{2}$ to $\mathrm{CO}$ inlet molar fraction can be produced by the gasifier;

- The analysis of the system global efficiency clearly says that the SOFC efficiency waste can be effectively recovered, obtaining high efficiency performance.

The use of a full 3D model for the SOFC simulation has been proved to be effective in the obtainment of accurate information on the distribution of the main thermal-fluid dynamics variables, and indicates the whole approach as a candidate to realize a reliable and comprehensive CAE tool for design and performance prediction starting from any SOFC configuration and fluid-dynamic arrangement.

\section{REFERENCES}

1. Achenbach E., SOFC Stack Modelling. Final Report on Activity A2, annex II. Modelling and Evaluation of Advanced Solid Oxide Fuel Cells, March 1996.

2. Achenbach E., Riensche E., Methane /Steam Reforming Kinetics for Solide Oxide Fuel Cells, J. Pow. Sources, 52,283-288, 1994.

3. Alauddin. Z.A, Performance and Characteristics of a Biomass Gasifier System, PhD Thesis, University of Wales, College of Cardiff, UK, 1996.

4. Autissier N., Larrain D., Van herle J., Favrat D., CFD Simulation tool for Solid Oxide Fuel Cells, J. Pow. Sources, 131, 313-319, 2004.

5. Campanari S., Iora P., Definition and Sensitivity Analysis of a Finite Volume SOFC Model for a Tubular Cell Geometry, J. Pow. Sources, 132:113128, 2004.

6. Chan S.H., Khor K.A., Xia Z.T., A Complete Polarization Model of a Solid Oxide Fuel Cell and its Sensitivity to the Change of Cell Component Thickness, J. Pow. Sources 93 130-140, 2001.

7. Douvartzides S.L., Coutelieris F.A., Demin A.K., Tsiakaras P.E., Fuel Options for Solid Oxide Fuel Cells: a Thermodynamic Analysis, AIChE J., 49, 248-257, 2003.

8. Ferguson J.R., Fiard J.M., Herbin R., Threedimensional Numerical Simulation for Various Geometries of Solid Oxide Fuel Cells, J. Pow. Sources 58, 109-122, 1996.

9. FLUENT 6.2, User Guide, Fluent, Inc., Lebanon, NH, 2004.

10. Hernandez-Pacheco E., Mann M.D., Hutton P. N., Singh D., Martin K. E., A Cell-level Model for a Solid Oxide Fuel Cell Operated with Syngas from a Gasification Process, Int. J. of Hyd. Energy 30, 1221-1233, 2005.

11. Hutton P.N., Musich M.A., Patel N., Schmidt D.D., Timpe R.C., Feasibility Study of a Thermally Integrated SOFC-gasification System for Biomass Power Generation. US Dept. of Energy National Energy Technology Laboratory Cooperative Agreement. Phase 1. Interim report, no. DE-FC26-
98FT40321, Energy \& Environmental Research Center-University of North Dakota, 2003.

12. Iwata M., Hikosaka T., Morita M., Iwanari T., Ito K., Onda K. et al., Performance Analysis of Planartype Unit SOFC Considering Current and Temperature Distributions, Solid State Ion, 132, 297-308, 2000.

13. Larminie J., Dicks A., Fuel Cell Systems Explained, Wiley \& Sons Ltd., 2000.

14. Matsuzaki Y., Yasuda I., The Poisoning Effect of Sulfur-Containing Impurity Gas on a SOFC Anode: Part I. Dependence on Temperature, Time and Impurity Concentration. Solid State Ion., 132:261269, 2000.

15. Motloch C.G., Thermochemical Modeling and Performance of a Methane Reforming Solid Oxide Fuel Cell, PhD Thesis, Idaho State University, 1998.

16. Omosun A.O., Bauen A., Brandon N.P., Adjiman C.S., Hart D., Modelling System Efficiencies and Costs of two Biomass-Fuelled SOFC Systems, J. Pow. Sources, 131, 96-106, 2004.

17. Pasaogullari U., Wang C.Y., Electrochem. Soc. Proc., 2003-07, 1403, 2003.

18. Pei-Wen Li, Chyu M.K., Simulation of the Chemical/electrochemical Reactions and Heat/mass Transfer for a Tubular SOFC in a Stack, J. Pow. Sources 124, 487-498, 2003.

19. Recknagle K.P., Williford R.E., Chick L.A., Rector D.R., Khaleel M.A., Three Dimensional ThermoFluid Electrochemical Modeling of Planar SOFC stacks, J. Pow. Sources, 113, 109-114, 2003.

20. Singh D., Hernandez Pacheco E., Hutton P.N., Patel N., Mann M.D., Carbon Deposition in a SOFC Fuelled by Tar-laden Biomass Gas: A Thermodynamic Analysis, J. Pow. Sources, 142 (12), 194-199, 2005.

21. Singhal S.C., Kendall K., High Temperature Solid Oxide Fuel Cells, Elsevier, 2003.

22. Wang C. Y., Fundamental Models for Fuel Cell Engineering, Chem. Rev., 104, 4727-4766, 2004.

23. Yakabe H., Ogiwara T., Hishimuma M., Yasuda I., 3D Model Calculation for Planar SOFC, J. Pow. Sources, 102:144-154, 2001.

24. Zainal Z.A., Ali R., Lean C.H., Seetharamu K.N., Prediction of Performance of a Downdraft Gasifier Using Equilibrium Modeling for Different Biomass Materials. En. Conv. and Manag. 42, 1499-1515, 2001. 